\title{
A study of metal/die interfacial heat transfer behavior of vacuum die cast pure copper
}

\author{
Hong-mei Yang 1, 2, 3, Zhou-meng Pü, Zhi-peng Guo 1,2, Ang Zhang, *Shou-mei Xiong ${ }^{1,2}$ \\ 1. School of Materials Science and Engineering, Tsinghua University, Beijing 100084, China \\ 2. Key Laboratory for Advanced Materials Processing Technology (Ministry of Education), Beijing 100084, China \\ 3. Yunnan Copper Die-casting Technology Co., Ltd., Kunming 650001, China
}

\begin{abstract}
High pressure die casting copper is used to produce rotors for induction motors to improve efficiency. Experiments were carried out for a special "step-shape" casting with different step thicknesses. Based on the measured temperature inside the die, the interfacial heat transfer coefficient (IHTC) at the metal/die interface during vacuum die casting was evaluated by solving the inverse problem. The IHTC peak value was $4.5 \times 10^{3}-$ $11 \times 10^{3} \mathrm{~W} \cdot \mathrm{m}^{-2} \cdot \mathrm{K}^{-1}$ under the basic operation condition. The influences of casting pressure, fast shot speed, pouring temperature and initial die surface temperature on the IHTC peak values were investigated. Results show that a greater casting pressure and faster shot speed could only increase the IHTC peak values at the location close to the ingate. An increase of pouring temperature and/or initial die surface temperature significantly increases the IHTC peak values.
\end{abstract}

Key words: vacuum die casting; interfacial heat transfer behavior; inverse method; copper; metal/die interface
CLC numbers: TG146.1+1
Document code: A
Article ID: 1672-6421 (202003-206-06

$\mathrm{C}$ opper rotors have been applied in induction motors for automotive vehicle and aviation industries ${ }^{[1-5]}$. Copper rotors are mostly produced by high pressure die casting (HPDC), which is one of the most economical processes for mass production ${ }^{[5]}$. However, gas pores and shrinkage porosity often appear in the end ring of copper rotors ${ }^{[6]}$. The presence of these defects significantly deteriorates the mechanical properties of the high-speed induction motor ${ }^{[7]}$. Vacuum die casting (VDC) ${ }^{[8]}$, together with modeling and simulation ${ }^{[9]}$ has been utilized to reduce gas porosity and produce high-integrity rotors. For modeling and simulation, the accuracy of the results is mostly dependent on the input boundary conditions, of which the metal/die interfacial heat transfer coefficient (IHTC) is shown to be crucial for the thermal field estimation. However, studies to evaluate the IHTC for the die casting copper process are very limited.

The IHTC was usually evaluated by solving an inverse heat conduction problem based on the temperature measurements inside the die. Guo et al. ${ }^{[10,11]}$ developed a special temperature sensor unit (TSU) to measure the

\section{*Shou-mei Xiong}

Male, Ph.D., Professor. Research interests: Al and Mg alloys high pressure die casting and microstructure simulation during solidification.

E-mail: smxiong@tsinghua.edu.cn

Received: 2019-12-18; Accepted: 2020-05-06 temperature during the HPDC process and evaluated the IHTC based on a one-dimensional inverse heat transfer model. The thermocouple tip was welded to the end wall of the groove inside the TSU to maintain a perfect contact. However, the thermocouple became detached from the end wall of the TSU during the HPDC process of copper because the die surface temperature approached $880{ }^{\circ} \mathrm{C}^{[12-14]}$, which was much higher than that when light alloys were used.

In this work, an optimized TSU was used during the die casting to obtain accurate temperatures. The influence of processing parameters, including casting pressure, fast shot speed, pouring temperature and initial die surface temperature on the IHTC was investigated.

\section{Experimental}

\subsection{Casting}

A "step-shape" casting was used in this study. As shown in Fig. 1, the "step-shape" casting has five different thicknesses, i.e., $d=1.5,3,6,10$ and $15 \mathrm{~mm}$ (marked as Step 1, Step 3, Step 6, Step 10 and Step 15, respectively).

\subsection{Die configuration and sensor installation}

An improved special temperature sensor unit (TSU) was used to measure the temperature inside the die. 
(a)

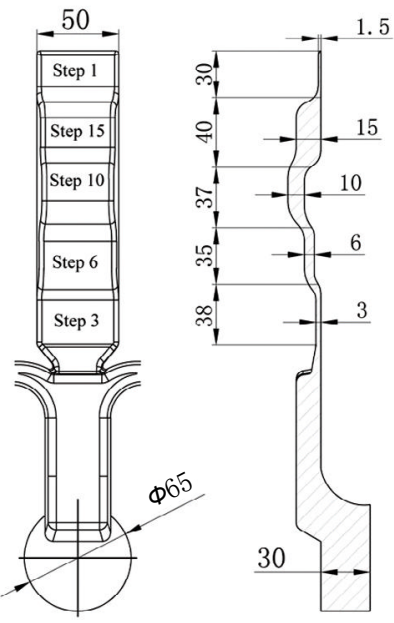

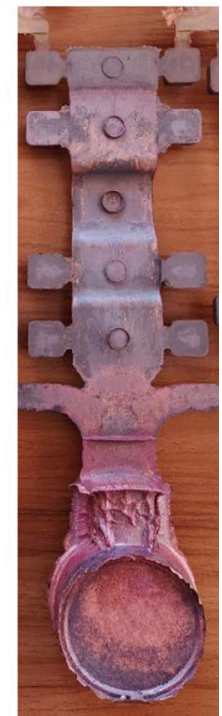

Fig. 1: Configuration of the "step-shape" casting: (a) size and geometry (unit: $\mathrm{mm}$ ); (b) actual casting
The die material was $4 \mathrm{Cr} 5 \mathrm{MoSiV} 1$. The thermocouples were held in a specific temperature sensor unit and fixed in grooves by a thermocouple fixed tool. As shown in Fig. 2, six grooves $1 \mathrm{~mm}$ wide and $1 \mathrm{~mm}$ deep were machined in the sensor unit for the placement of the thermocouples. At each distance (1, 3, and $6 \mathrm{~mm}$ ) from the front wall of the TSU, two thermocouples were fixed (i.e. A1 and A2, B1 and B2, C1 and C2). The thermocouples were $\mathrm{K}$-type thermocouples with a diameter of $1 \mathrm{~mm}$ (the wire diameter was $0.045 \mathrm{~mm}$ ).

Figure 3 shows the installation of the TSU inside the die. Five temperature sensor units, designated as TSU1-TSU5, were installed inside the fixed die corresponding to each step.

\subsection{Material characterization and the inverse method}

Tables 1-3 show the chemical compositions and thermophysical properties of copper and $4 \mathrm{Cr} 5 \mathrm{MoSiV} 1$, respectively.

The "step-shape" casting was produced on a Buhler cold chamber die casting machine equipped with a vacuum system

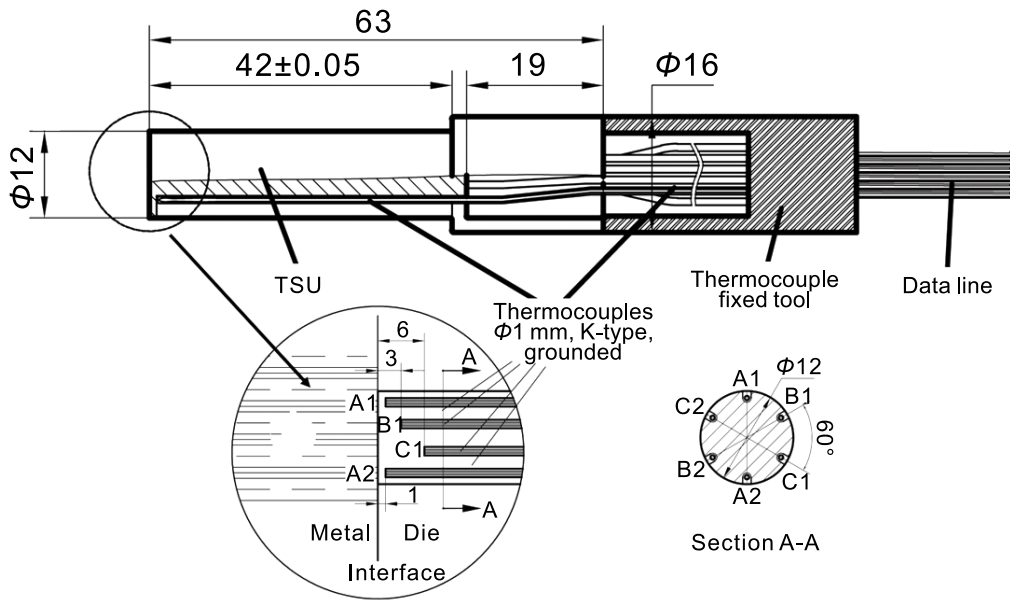

Fig. 2: Configuration of improved temperature sensor unit

Table 1: Chemical composition of copper (wt.\%)

$\begin{array}{ccccccccc}\mathrm{Cu}+\mathrm{Ag} & \mathrm{S} & \mathrm{P} & \mathrm{Fe} & \mathrm{Pb} & \mathrm{Zn} & \mathrm{As} & \mathrm{Sb} & \mathrm{Bi} \\ \geq 99.97 & \leq 0.0025 & \leq 0.001 & \leq 0.0025 & \leq 0.002 & \leq 0.002 & \leq 0.0015 & \leq 0.0015 & \leq 0.0006\end{array}$

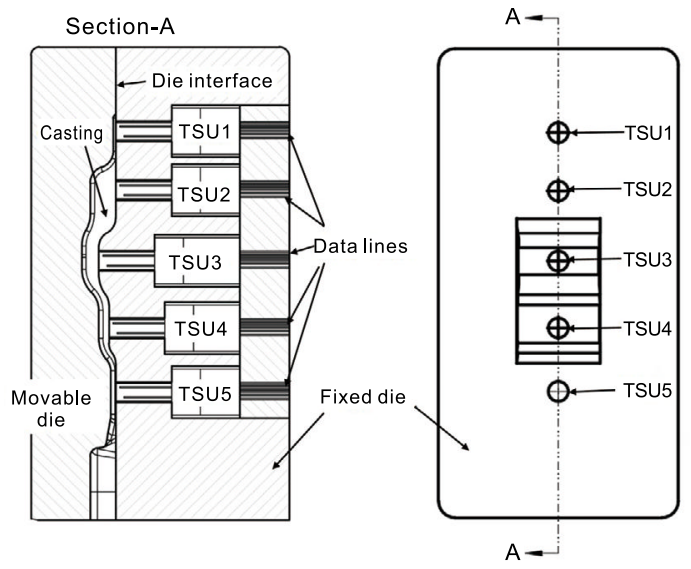

Fig. 3: Schematic illustration of TSU installation inside the die
Table 2: Chemical composition of 4Cr5MoSiV1 steel (wt.\%)

\begin{tabular}{ccccccccc} 
C & Mn & Si & S & P & Cr & Mo & V & Fe \\
\hline 0.396 & 0.36 & 0.94 & $<0.005$ & $<0.025$ & 5.05 & 1.25 & 0.82 & Bal.
\end{tabular}

and chill vent. The vacuum pressure in the cavity managed to approach $10 \mathrm{kPa}$, using a vacuum system as described by Wang et al ${ }^{[15]}$. The die was preheated to $200{ }^{\circ} \mathrm{C}$, and a total of 45 castings were produced under the basic operation condition (Table 4). Processing parameters including pouring temperature, casting pressure and fast shot speed were varied (Table 4), and five shots were performed for each operation condition. The temperature was recorded using a data acquisition system manufactured by Integrated Measurement Corporation with a data acquisition frequency of $500 \mathrm{~Hz}$. 
Table 3: Thermal properties of copper and 4Cr5MoSiV1

\begin{tabular}{|ccc|}
\hline Thermal properties & Copper & 4Cr5MoSiV1 \\
\hline Thermal conductivity, $\Lambda\left(\mathrm{W} \cdot \mathrm{m}^{-1} \cdot \mathrm{K}^{-1}\right)$ & 398 & $31.2-0.013 T^{\mathrm{a}}$ \\
Specific heat, $C_{\mathrm{p}}\left(\mathrm{J} \cdot \mathrm{kg}^{-1} \cdot \mathrm{K}^{-1}\right)$ & 386 & $478-0.219 T$ \\
Density, $\rho\left(\mathrm{kg} \cdot \mathrm{m}^{-3}\right)$ & 8,900 & $7,730-0.24 T$ \\
Solidus temperature, $T_{\mathrm{S}}\left({ }^{\circ} \mathrm{C}\right)$ & 1,065 & 1,471 \\
Liquidus temperature, $T_{\mathrm{L}}\left({ }^{\circ} \mathrm{C}\right)$ & 1,083 & 1,404 \\
Latent heat, $L_{\mathrm{s}}\left(\mathrm{J} \cdot \mathrm{kg}^{-1}\right)$ & 211,500 & 209,350
\end{tabular}

${ }^{\mathrm{a}} \mathrm{T}$ stands for temperature $\left({ }^{\circ} \mathrm{C}\right)$

Table 4: Processing parameters during the experiment

\begin{tabular}{ccc} 
Processing parameters & Basic & Variable \\
\hline Pouring temperature $\left(T_{\mathrm{p}},{ }^{\circ} \mathrm{C}\right)$ & 1,200 & 1,300 \\
Initial die temperature $\left(T_{\mathrm{m}},{ }^{\circ} \mathrm{C}\right)$ & 300 & $200-450$ \\
Casting pressure $(\mathrm{MPa})$ & 87 & 60 \\
Slow shot speed $\left(V_{\mathrm{L}}, \mathrm{m} \cdot \mathrm{s}^{-1}\right)$ & 0.5 & \\
Fast shot speed $\left(V_{\mathrm{H}}, \mathrm{m} \cdot \mathrm{s}^{-1}\right)$ & 2 & 3.5
\end{tabular}

The IHTC was estimated by solving an inverse heat condition problem based on the principle proposed by Beck et al ${ }^{[16,17]}$. The target is to minimize the sum of the squared errors between the calculated and the measured data:

$$
F(h)=\sum_{i=1}^{N}\left(T_{i}-Y_{i}\right)^{2} \rightarrow \min
$$

where $T_{i}$ and $Y_{i}$ are calculated and measured temperatures at various thermocouple locations, respectively, and $N$ designates the number of future time steps.

\section{Results and discussion}

\subsection{Validation of measured temperatures}

Figure 4 shows the measured temperature curves inside the die according to Step 6 under the basic operation condition. The temperature curves measured at each distance in the sensor unit, such as $T_{\mathrm{A} 1}$ and $T_{\mathrm{A} 2}$ or $T_{\mathrm{C} 1}$ and $T_{\mathrm{C} 3}$, are almost overlapping. The largest difference was $\sim 7^{\circ} \mathrm{C}$, indicating that the one-dimensional heat-transfer assumption was reasonable ${ }^{[18]}$. The IHTC was determined based on the temperature measurements at $1 \mathrm{~mm}$ (average of $T_{\mathrm{A} 1}$ and $T_{\mathrm{A} 2}$ ) and $6 \mathrm{~mm}$ (average of $T_{\mathrm{C} 1}$ and $T_{\mathrm{C} 2}$ ) away from the cavity surface. The temperature measurements at $3 \mathrm{~mm}$ (average of $T_{\mathrm{B} 1}$ and $T_{\mathrm{B} 2}$ ) away from the cavity surface were compared with the inversely determined temperatures to testify the accuracy of the inverse model. Figure 5 shows that the measured and simulated temperatures at $3 \mathrm{~mm}\left(T_{3 \mathrm{~m}}\right.$ and $T_{3 \mathrm{c}}$ ) agreed well with each other and a maximum difference was about $5{ }^{\circ} \mathrm{C}$, indicating the accuracy of model.

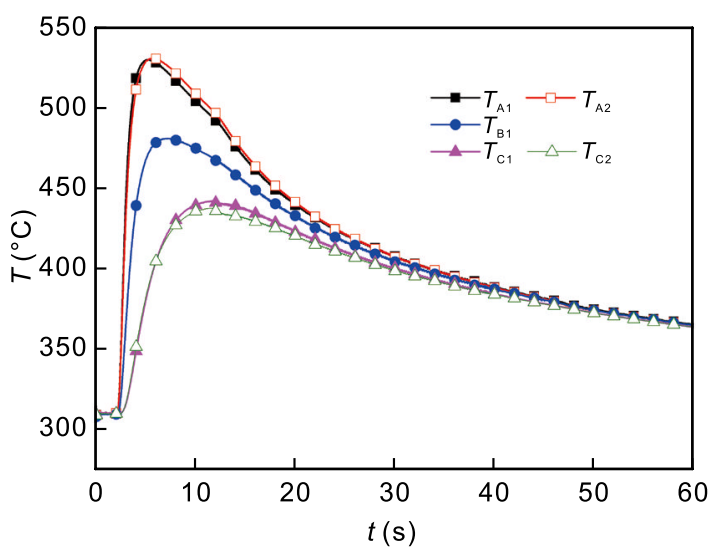

Fig. 4: Measured temperatures inside the die at Step 6 under basic operation condition

\subsection{Interfacial heat transfer behavior during VDC}

Figure 5 shows the determined IHTC and heat flux profiles at Step 6 . The surface temperature of copper decreased immediately after the melt contacted the die surface. The IHTC increased abruptly until reaching a maximum of $4.76 \times 10^{3} \mathrm{~W} \cdot \mathrm{m}^{-2} \cdot \mathrm{K}^{-1}$. The heat flux also increased rapidly until reaching $2.96 \times 10^{6} \mathrm{~W} \cdot \mathrm{m}^{-2}$. The IHTC then decreased rapidly until reaching a lower value of $2.48 \times 10^{3} \mathrm{~W} \cdot \mathrm{m}^{-2} \cdot \mathrm{K}^{-1}$. At the later stage of solidification, the contact between the casting and the die deteriorated, and the IHTC became lower than $1,000 \mathrm{~W} \cdot \mathrm{m}^{-2} \cdot \mathrm{K}^{-1}$.

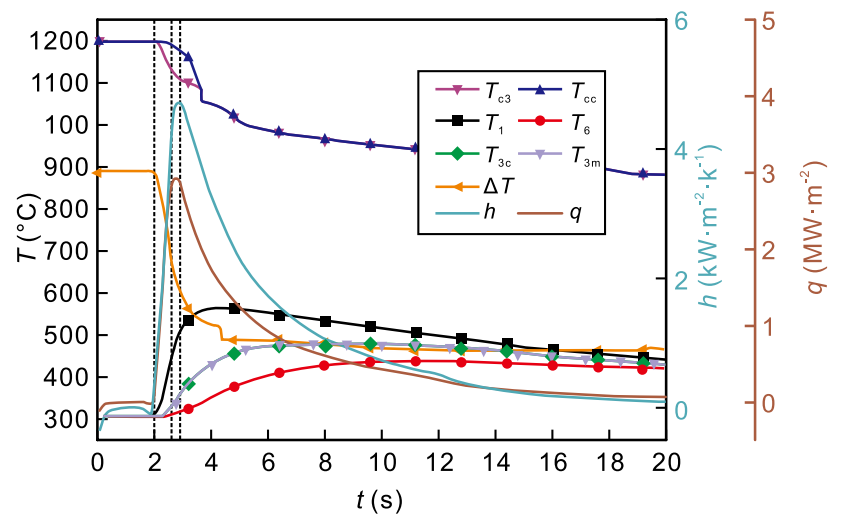

Fig. 5: Measured temperatures and determined IHTC at Step $6\left(T_{\mathrm{cs}}, T_{\mathrm{cc}}\right.$ - the inversely calculated temperatures of the step surface and center; $T_{1}, T_{6}$ - average measured temperatures at $1 \mathrm{~mm}$ and $6 \mathrm{~mm}$ away from the cavity surface; $T_{3 m}$-average measured temperatures at $3 \mathrm{~mm}$ away from the cavity surface; $T_{3 c}$-the inversely calculated temperature at $3 \mathrm{~mm}$ away from the cavity surface; $\Delta T$-the temperature difference between metal and die surfaces; $h$-the interfacial heat transfer coefficient; $q$-the interfacial heat flux density)

Figure 6 shows the calculated IHTC profiles at five steps under the basic condition. All IHTC profiles changed similarly as that at Step 6. The IHTC always exhibited an abrupt increase after filling until reaching its maximum value, and then decreased to a much lower level. Despite the difference of the IHTC peak value $\left(h_{\max }\right)$, the duration for the IHTC to maintain a higher value increased with the step thickness 


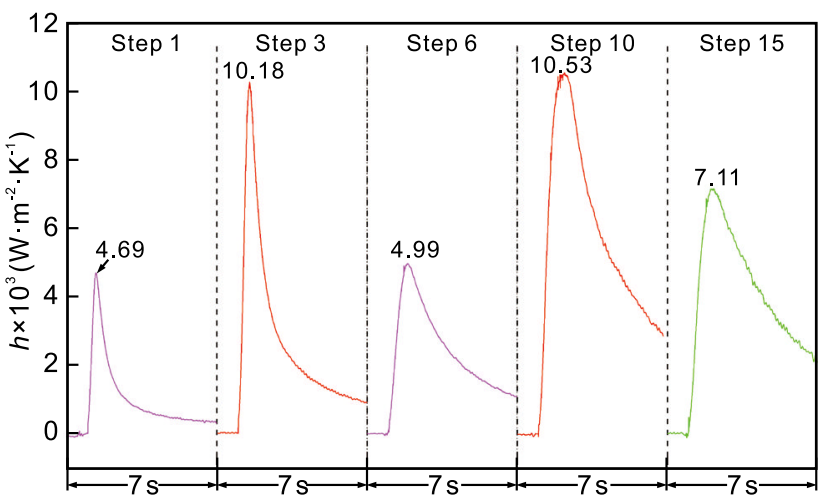

$t(\mathrm{~s})$

Fig. 6: Determined IHTC profiles at five steps under basic condition (such duration was $0.064 \mathrm{~s}$ for Step 1, $0.136 \mathrm{~s}$ for Step 6 and $0.46 \mathrm{~s}$ for Step 10, respectively). The IHTCs at Steps 1 and 3 dropped much faster than other steps. It took much longer for the IHTC to decrease when the step thickness was greater. Figure 7 shows the filling process of the liquid copper simulated by a CAE cloud computing platform namely Ares by Supreium Co. Ltd. under the basic operation condition. The melt copper flowed inside the cavity of Step 3 from the gating system towards the surface of the fixed die inside which the temperature sensor units were installed. The flow then moved toward the surface of the movable die until reaching the cavity of Step 15 where the direction of the flow changed. In this respect, the melt flowed directly towards the fixed die surface for Steps 3, 15 and 1, and towards the movable die surface for Steps 6 and 10. The heat transfer during the initial increasing

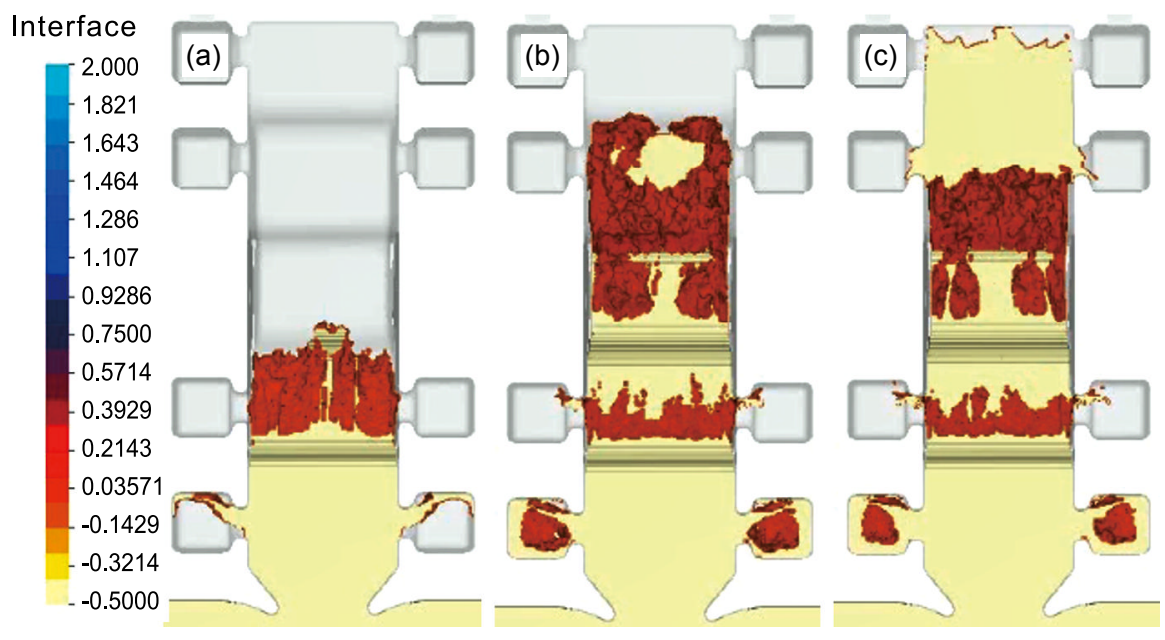

Fig. 7: Simulation of the filling process inside the "step-shape" casting (a) Steps 3 and 6; (b) Steps 6 and 10; (c) Steps 15 and 1

stage was dependent on such filling behavior, but the peak value of the determined IHTC was greatly dependent on the contact status between the alloy melt and the die.

Comparing the results of the five steps, the peak values of IHTC exhibited three levels. It was about $5 \times 10^{3} \mathrm{~W} \cdot \mathrm{m}^{-2} \cdot \mathrm{K}^{-1}$ for Steps 1 and 6 , and $7 \times 10^{3} \mathrm{~W} \cdot \mathrm{m}^{-2} \cdot \mathrm{K}^{-1}$ for Step 15 . The larger peak values of IHTC were $\sim 10 \times 10^{3} \mathrm{~W} \cdot \mathrm{m}^{-2} \cdot \mathrm{K}^{-1}$ for Steps 3 and
10. The difference between every two levels was about 2,000$3,000 \mathrm{~W} \cdot \mathrm{m}^{-2} \cdot \mathrm{K}^{-1}$

\subsection{Influence of processing parameters}

Figure 8 shows the influence of the casting pressure and fast shot speed on the IHTC peak values. The IHTC peak value at Step 3 increased from $10.5 \times 10^{3}$ to $11.3 \times 10^{3} \mathrm{~W} \cdot \mathrm{m}^{-2} \cdot \mathrm{K}^{-1}$ as
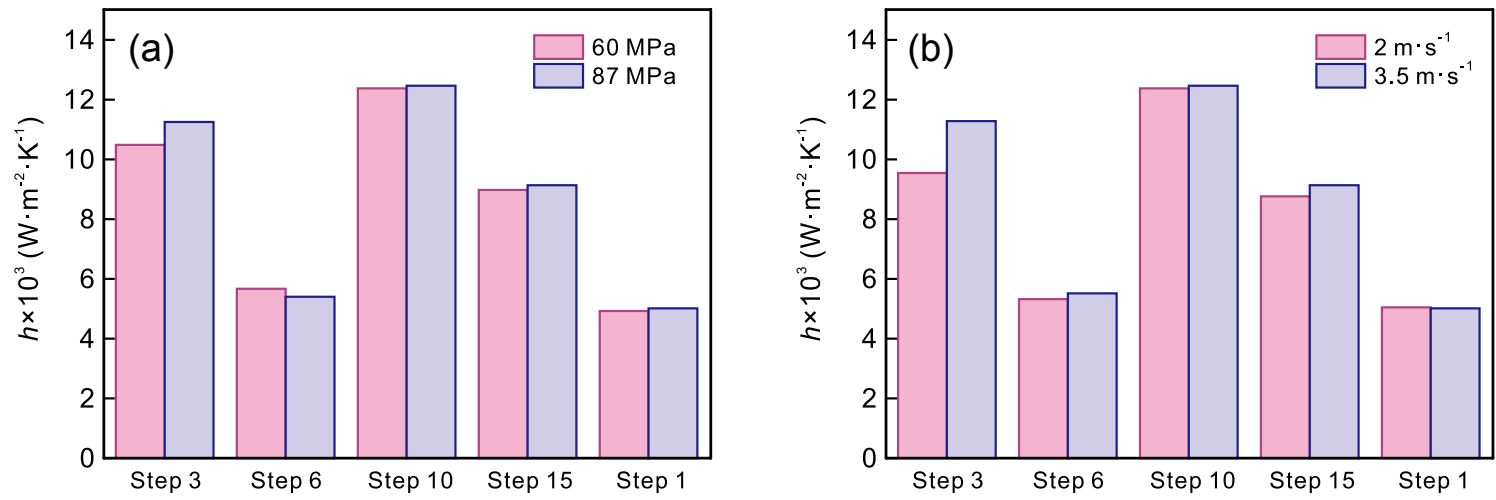

Fig. 8: Calculated IHTC peak values under different casting pressures (a) and fast shot speeds (b) 
the casting pressure increased. The IHTC peak values hardly changed for other steps when the pressure was varied. This is because a better contact was achieved between the casting and the die when the vacuum die casting was applied. Besides, the casting pressure could not be effectively transferred farther away from the ingate due to solidification ${ }^{[19]}$. The influence of fast shot speed on the IHTC was similar (Fig. 8b). As the fast shot speed increased, the IHTC peak value at Step 3 increased from $9.5 \times 10^{3}$ to $11.3 \times 10^{3} \mathrm{~W} \cdot \mathrm{m}^{-2} \cdot \mathrm{K}^{-1}$, and slightly increased for other steps. A faster shot speed induced a stronger impact between the molten metal and the die during filling.

Figure 9 shows $h_{\max }$ under different pouring temperatures. Increasing the pouring temperature from $1,200{ }^{\circ} \mathrm{C}$ to $1,300{ }^{\circ} \mathrm{C}$ led to an increase of $h_{\max }$ by $33.6 \%$ at Step 3, 19.6\% at Step 6, 22.0\% at Step $10,25.3 \%$ at Step 15, and $4 \%$ at Step 1. The IHTC peak value increased from $10.7 \times 10^{3}$ to $14.3 \times 10^{3} \mathrm{~W} \cdot \mathrm{m}^{-2} \cdot \mathrm{K}^{-1}$ at Step 3 near the gate and from $4.9 \times 10^{3}$ to $5.1 \times 10^{3} \mathrm{~W} \cdot \mathrm{m}^{-2} \cdot \mathrm{K}^{-1}$ at Step1 near the overflow, respectively.

Figure 10(a) shows the IHTC peak values as a function of the initial die surface temperature at Step 6 under basic condition. The IHTC peak values increased when the initial die surface temperature increased. Figure 10(b) shows the change of IHTC peak values $\left(h_{\max }\right)$ versus initial die surface temperature $\left(T_{\text {IDS }}\right)$ at five steps under the basic condition. According to Ref. [20], the IHTC peak values $\left(h_{\max }\right)$ changed

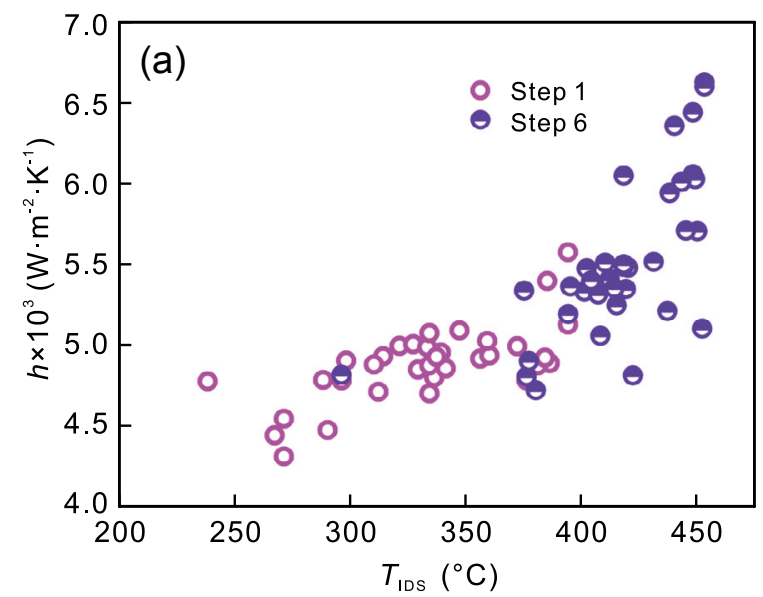

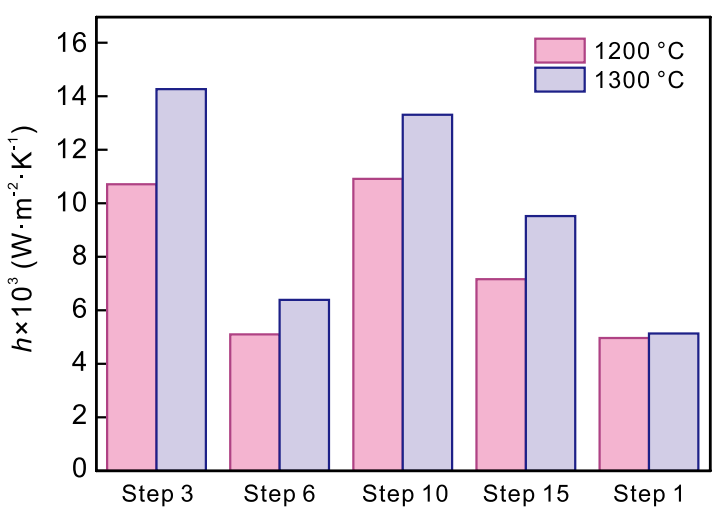

Fig. 9: Estimated IHTC peak values under different pouring temperatures

as a function of $T_{\mathrm{IDS}}$ :

$$
\ln \eta_{\mathrm{h}}=\ln \left(h_{\mathrm{max}} / T_{\mathrm{IDS}}^{2}\right)=A \ln T_{\mathrm{IDS}}+B
$$

where $\mathrm{A}$ and $\mathrm{B}$ are fitted parameters. $h_{\max }$ was:

$$
h_{\text {max }}=e^{\mathrm{B}} \times T_{\mathrm{IDS}}^{2+\mathrm{A}}
$$

Equation (3) illustrates $h_{\max }$ changes as a function of $T_{\text {IDS }}$. The largest variance or deviation was $12.2 \%$ for steps 3 and 10 . It is found that $\ln \eta_{\mathrm{h}}$ decreased as $\ln T_{\text {IDS. }}$. The initial die surface temperature $\left(T_{\mathrm{IDS}}\right)$ exhibited the most dominant influence on the IHTC peak value.

Fig. 10: IHTC peak values as a function of the initial die surface temperature at Steps 1 and 6 (a) and five steps under the basic conditions (b)

\section{Conclusions}

In this work, the interfacial heat transfer coefficient (IHTC) between copper and die during vacuum die casting was estimated by solving an inverse thermal problem based on the measured temperatures inside the die. The influence of processing parameters on the IHTC was investigated, based on which the following conclusions can be drawn:

(1) During the die casting process, the IHTC first increases abruptly to a maximum when the liquid metal comes in contact with the die surface, then decreases until the value approaches

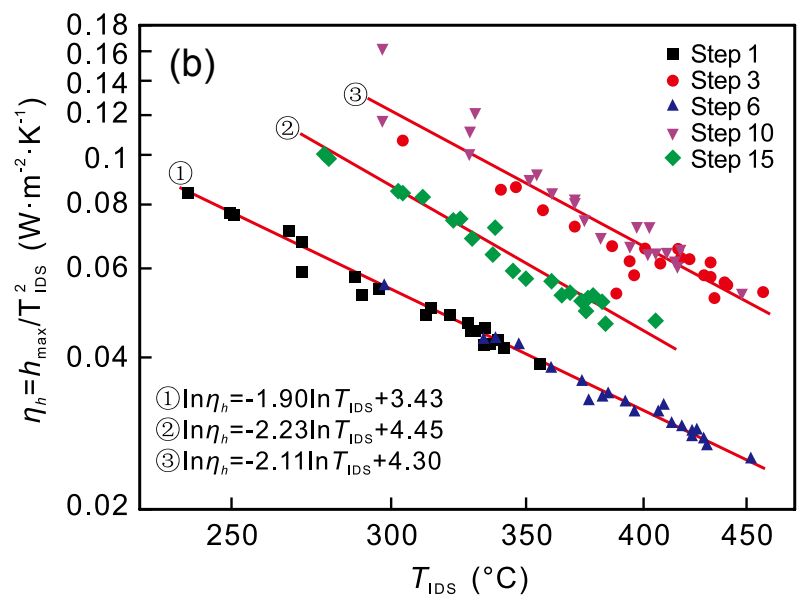

a much lower level.

(2) Under the basic operation condition, the IHTC peak values are $5 \times 10^{3} \mathrm{~W} \cdot \mathrm{m}^{-2} \cdot \mathrm{K}^{-1}$ at Steps 1 and $6,7 \times 10^{3} \mathrm{~W} \cdot \mathrm{m}^{-2} \cdot \mathrm{K}^{-1}$ at Step 15 , and $10 \times 10^{3} \mathrm{~W} \cdot \mathrm{m}^{-2} \cdot \mathrm{K}^{-1}$ at Steps 3 and 10 , respectively.

(3) The IHTC peak values are shown to be dependent on the processing parameters. As the casting pressure and the fast shot speed increase, the IHTC peak values increase at Step 3 near the gate, whereas the IHTC at other steps changes insignificantly. As the pouring temperature increases from $1,200{ }^{\circ} \mathrm{C}$ to $1,300{ }^{\circ} \mathrm{C}$, the IHTC increases significantly at all steps. 
(4) The IHTC peak values are mostly dominated by the initial die surface temperature according to $h_{\max }=e^{\mathrm{B}} \times T_{\mathrm{IDS}}^{2+\mathrm{A}}$.

\section{References}

[1] Bárdos A, Walczer C, Kéri Z, et al. Copper rotor technology for high efficiency motors. In: Jármai K, Bolló B (eds), Vehicle and Automotive Engineering 2, Springer, 2018: 186-198.

[2] Lie S, Pietro C D. Copper die-cast rotor efficiency improvement and economic consideration. IEEE Transactions on Energy Conversion, 1995, 10(3): 419-424.

[3] Bárdos A, Braun W, Doppelbauer M. Two frequently development ways of induction motors: High efficiency and high-speed drives. In: Proc. 4th International Conference on Magnetism and Metallurgy, Freiberg, Germany, 2010: 387390.

[4] Epskamp T, Butz B, Doppelbauer M. Design and analysis of a high-speed induction machine as electric vehicle traction drive. In: Proc.18th European Conference on Power Electronics and Applications, Karlsruhe, Germany, 2016: 1-10.

[5] Peters D T, Cowie J G, Jr. Brush E F. Performance of motors with die-cast copper rotors in industrial and agricultural pumping applications. In: Proc. IEEE International Electric Machines and Drives Conference, San Antonio, TX, USA, 2005: 987-992.

[6] Brush E F, Midson S P, Walkington W G. Porosity control in copper rotor die castings. In: Proc. Die Casting Congress, NADCA, Indianapolis, India, 2010.

[7] Hong D K, Choi J H, Kim D J, et al. Development of a high speed induction motor for spindle systems. IEEE Transactions On Magnetics, 2013, 49(7): 4088-4091.

[8] Yang Hongmei, Guo Zhipeng, Yang Huazhong, et al. Effect of vacuum on porosity and mechanical properties of highpressure die-cast pure copper. China Foundry, 2019, 16(4): 232-237.

[9] Badarinarayan H, Takahashi I, Cowie J, et al. Numerical simulation of copper rotor die casting with validation using X-ray computed tomography. The North American Die casting Association, 241 Holbrook, Wheeling, Illinois: 2005.
[10] Guo Zhipeng, Xiong Shoumei, Liu Baicheng, et al. Determination of the heat transfer coefficient at metal-die interface of high pressure die casting process of AM50 alloy. International Journal of Heat \& Mass Transfer, 2008, 51(25): 6032-6038.

[11] Guo Zhipeng, Xiong Shoumei, Cho Sang Hyun, et al. Interfacial heat transfer coefficient between metal and die during high pressure die casting process of aluminum alloy. Frontiers of Mechanical Engineering in China, 2007, 2(3): 283-287.

[12] Peters D T, Brush E F, Cowie J G. Use of high temperature die material \& hot dies for high pressure die casting pure copper and copper alloys. In: Proc. Die Casting Congress, NADCA, Rosemont, IL, 2002, T02-65: 1-7.

[13] Peters D T, Cowie J G, Brush E F. The die-cast copper motor rotor - A new copper market opportunity. https://www.copper.org, 2002.

[14] Cowie J G, Peters D T, Brush E F, et al. Materials \& modifications to die cast the copper conductors of the induction motor rotor. Die Casting Engineer, 2001, 45(5): 38-46.

[15] Wang Qingliang, Xiong Shoumei. Vacuum assisted highpressure die casting of AZ91D magnesium alloy at different slow shot speeds. Transactions of Nonferrous Metals Society of China, 2014, 24(10): 3051-3059.

[16] Blanc G, Beck J V, Raynaud M. Solution of the inverse heat conduction problem with a time-variable number of future temperatures. Numerical Heat Transfer Part B: Fundamentals, 1997, 32(4): 437-451.

[17] Beck J V. Surface heat flux determination using an integral method. Nuclear Engineering \& Design, 1968, 7(2): 170-178.

[18] Guo Zhipeng, Xiong Shoumei, Liu Baicheng, et al. Effect of process parameters, casting thickness, and alloys on the interfacial heat-transfer coefficient in the high-pressure diecasting process. Metallurgical \& Materials Transactions A, 2008, 39(12): 2896-2905.

[19] Guo Zhipeng, Xiong Shoumei, Liu Baicheng, et al. Determination of the metal/die interfacial heat transfer coefficient and its application in evaluating the pressure distribution inside the casting during the high pressure die casting process. International Journal of Cast Metals Research, 2013, 22(1-4): 327-330.

[20] Cao Yongyou, Guo Zhipeng, Xiong Shoumei. Determination of interfacial heat transfer coefficient and its application in high pressure die casting process. China Foundry, 2014, 11(4): 314-321. 